\title{
Early treatment with tolvaptan improves diuretic response in acute heart failure with renal dysfunction
}

\author{
Yuya Matsue $^{1,2}$ (1) Jozine M. ter Maaten ${ }^{1} \cdot$ Makoto Suzuki $^{2} \cdot$ Sho Torii ${ }^{3} \cdot$ \\ Satoshi Yamaguchi ${ }^{4} \cdot$ Seiji Fukamizu $^{5} \cdot$ Yuichi Ono $^{6} \cdot$ Hiroyuki Fujii $^{7}$. \\ Takeshi Kitai $^{8}$ - Toshihiko Nishioka9 ${ }^{9}$ Kaoru Sugi ${ }^{10}$ - Yuko Onishi ${ }^{11}$. \\ Makoto Noda ${ }^{12}$ Nobuyuki Kagiyama ${ }^{13}$ - Yasuhiro Satoh $^{14} \cdot$ Kazuki Yoshida $^{15}$. \\ Peter van der Meer $^{1} \cdot$ Kevin Damman $^{1} \cdot$ Adriaan A. Voors $^{1} \cdot$ Steven R. Goldsmith $^{16}$
}

Received: 8 March 2017 / Accepted: 19 May 2017/Published online: 24 May 2017

(c) The Author(s) 2017. This article is an open access publication

\begin{abstract}
Background Poor response to diuretics is associated with worse prognosis in patients with acute heart failure (AHF). We hypothesized that treatment with tolvaptan improves diuretic response in patients with AHF.

Methods We performed a secondary analysis of the AQUAMARINE open-label randomized study in which a total of 217 AHF patients with renal impairment (eGFR $<60 \mathrm{~mL} / \mathrm{min} / 1.73 \mathrm{~m}^{2}$ ) were randomized to either tolvaptan or conventional treatment. We evaluated diuretic response to $40 \mathrm{mg}$ furosemide or its equivalent based on
\end{abstract}

Electronic supplementary material The online version of this article (doi:10.1007/s00392-017-1122-1) contains supplementary material, which is available to authorized users.

Yuya Matsue

yuya8950@gmail.com

1 Department of Cardiology, University of Groningen, University Medical Center Groningen, Groningen, The Netherlands

2 Department of Cardiology, Kameda Medical Center, 929, Higashi-Cho, Kamogawa, Chiba, Japan

3 Department of Cardiology, Tokai University School of Medicine, Kanagawa, Japan

4 Department of Cardiology, Tomishiro Central Hospital, Okinawa, Japan

5 Department of Cardiology, Tokyo Metropolitan Hiroo Hospital, Tokyo, Japan

6 Department of Cardiology, Ome Municipal General Hospital, Tokyo, Japan

7 Department of Cardiology, Yokohama Minami Kyosai Hospital, Kanagawa, Japan two different parameters: change in body weight and net fluid loss within $48 \mathrm{~h}$.

Results The mean time from patient presentation to randomization was $2.9 \mathrm{~h}$. Patients with a better diuretic response showed greater relief of dyspnea and less worsening of renal function. Tolvaptan patients showed a significantly better diuretic response measured by diuretic response based both body weight $[-1.16$ (IQR -3.00 to -0.57 ) $\mathrm{kg} / 40 \mathrm{mg}$ vs. -0.51 (IQR -1.13 to -0.20 ) $\mathrm{kg} /$ $40 \mathrm{mg} ; \quad P<0.001]$ and net fluid loss [2125.0 (IQR 1370.0-3856.3) $\mathrm{mL} / 40 \mathrm{mg}$ vs. 1296.3 (IQR 725.2-1726.5) $\mathrm{mL} / 40 \mathrm{mg} ; P<0.001]$. Higher diastolic blood pressure and use of tolvaptan were independent predictors of a better diuretic response.

Conclusions Better diuretic response was associated with greater dyspnea relief and less WRF. Early treatment with

8 Department of Cardiovascular Medicine, Kobe City Medical Center General Hospital, Kobe, Japan

9 Department of Cardiology, Saitama Medical Center, Saitama Medical University, Kawagoe, Japan

10 Division of Cardiovascular Medicine, Toho University Ohashi Medical Center, Tokyo, Japan

11 Department of Cardiology, Hiratsuka Kyosai Hospital, Kanagawa, Japan

12 Department of Cardiology, Tokyo Yamate Medical Center, Tokyo, Japan

13 Department of Cardiology, The Sakakibara Heart Institute of Okayama, Okayama, Japan

14 Department of Cardiology, National Disaster Medical Center, Tokyo, Japan

15 Department of Epidemiology, Harvard T. H. Chan School of Public Health, Boston, MA, USA

16 Division of Cardiology, Hennepin County Medical Center and University of Minnesota, Minneapolis, MN, USA 
tolvaptan significantly improved diuretic response in AHF patients with renal dysfunction.

Keywords Acute heart failure - Diuretics · Worsening renal function - Dyspnea relief

\section{Introduction}

Volume overload and subsequent congestion are the primary causes and treatment targets for acute heart failure (AHF) $[1,2]$. Diuretics have, therefore, been the mainstay of treatment of patients with AHF [3]. Recent studies, however, have suggested that there are patients with AHF who may be refractory to conventional diuretic therapy $[4,5]$. This poor diuretic response is a strong and independent predictor of unfavorable prognosis [6], and no therapy has yet been proven to benefit patients with a poor diuretic response.

Tolvaptan is an oral, non-peptide, selective vasopressin2 receptor antagonist, and prevents the activation of the aquaporin system and impairs the ability of the kidney to reabsorb water; as a result, free water excretion is increased. In the Efficacy of Vasopressin Antagonism in Heart Failure Outcome Study With Tolvaptan (EVEREST) trial, tolvaptan showed a favorable short-term effect but neutral long-term effect in AHF patients [7]. However, in this trial AHF patients were enrolled relatively late after presentation as a consequence of inclusion criteria $(<48 \mathrm{~h}$ from hospitalization). Recent AHF studies have showed "time to treatment" is a factor associated with drug efficacy and patient prognosis [8, 9] and the latest European Society of Cardiology heart failure guideline emphasizes the importance of treating AHF patients as quickly as possible [10]. Therefore, treatment with tolvaptan in the very early phase worth evaluating. Moreover, no study has evaluated diuretic response in Asian AHF patients. In the AQUAMARINE study (a randomized study evaluated efficacy of tolvaptan in patients with AHF and renal dysfunction), all patients were randomized within $6 \mathrm{~h}$ from hospitalization. Consequently, median time from first presentation to randomization was $2.1 \mathrm{~h}$. In this study, we aimed to evaluate the effect of early treatment with tolvaptan on diuretic response in AHF patients with concomitant renal dysfunction.

\section{Methods}

\section{Study population}

This is a retrospective secondary analysis of the AQUAMARINE study. The study design and primary results of
AQUAMARINE have been described elsewhere [11, 12]. In brief, 217 patients with $\mathrm{AHF}$ and renal dysfunction (estimated glomerular filtration rate, $15-60 \mathrm{~mL} / \mathrm{min} /$ $1.73 \mathrm{~m}^{2}$ ) were randomized within $6 \mathrm{~h}$ from hospitalization into two groups, either tolvaptan treatment or conventional treatment, to evaluate the efficacy of early treatment with tolvaptan. Fifty-three patients $(48.6 \%)$ in the tolvaptan group received tolvaptan for more than 2 days, and no patient who was initially allocated to conventional group crossed over to tolvaptan during the first $48 \mathrm{~h}$. The protocol of the study was approved by the ethics committees of all participating centers, and written informed consent was obtained from all the participants. This trial was registered at UMIN-CTR (Unique identifier: UMIN000007109).

\section{Data collection}

In the AQUAMARINE study, data regarding blood pressure, heart rate, and improvement in dyspnea from baseline and blood samples were collected at 6, 12, 24, and $48 \mathrm{~h}$ from enrollment. Dyspnea was assessed according to the patient-reported seven-point Likert scale. Within $48 \mathrm{~h}$, the amount of furosemide-equivalent loop diuretics, change in body weight from baseline, and urine output were noted down. Worsening renal function was defined as an increase of $\geq 0.3 \mathrm{mg} / \mathrm{dL}$ in the serum creatinine from the baseline at various pre-specified time points $(6,12,24$, and $48 \mathrm{~h}$ from randomization). The incidence of the combined endpoints for all-cause mortality and re-hospitalization for heart failure within 90 days was also evaluated.

\section{Diuretic response}

We defined diuretic response as the change in body weight (kg) from baseline to $48 \mathrm{~h}$ per $40 \mathrm{mg}$ intravenous furosemide administration. Oral furosemide was converted to half the dose of intravenous furosemide. The doses of oral loop diuretics that were considered equivalent to $40 \mathrm{mg}$ intravenous furosemide were $10 \mathrm{mg}$ torasemide and $60 \mathrm{mg}$ azosemide [13, 14]. We also performed analyses using net fluid loss within $48 \mathrm{~h}$ as a measure of diuretic response. Diuretic response was measured according to body weight change in 189 cases after excluding 28 cases due to missing data on the total diuretic dose $(n=3)$ and body weight change $(n=25)$. Data on diuretic response based on net fluid loss were achieved in 171 cases and missing in 46 cases due to unavailability of information on water intake in 45 cases and on furosemide dose in 3 cases.

\section{Statistical analysis}

Data were expressed as mean \pm standard deviation for normally distributed variables and as median with 
interquartile range (IQR) for non-normally distributed data. Categorical data were expressed as numbers and percentages. The relationships between baseline characteristics, outcomes and tertiles of diuretic response were compared by one-way analysis of variance, Kruskal-Wallis test, or $\chi^{2}$ test, as appropriate. Correlation analysis was performed using Spearman's rho. When necessary, variables were transformed for further analyses. Stepwise multiple linear regression analysis was performed using backward elimination method after including all variables with $P$ values below 0.10 in the univariate analysis. Statistical analyses were performed using $\mathrm{R}$ version 3.1.2.

\section{Results}

In the AQUAMARINE study, 220 patients were originally enrolled, of which 217 were analyzed because one patient in the tolvaptan group and one patient in the conventional group withdrew their consent and data were missing for one patient in the tolvaptan group. The baseline characteristics of randomized patients were shown elsewhere [12]. The median age of the patients was 75 years (interquartile range [IQR], 68-81 years), and $64.9 \%$ was male. The median left ventricular ejection fraction was $44.5 \%$, and $82(37.8 \%)$ patients had a left ventricular ejection fraction $\geq 50 \%$. Mean baseline eGFR was $40.5 \mathrm{~mL} / \mathrm{min} / 1.73 \mathrm{~m}^{2}$, and 57 (26.3\%) patients had an eGFR $<30 \mathrm{~mL} / \mathrm{min} / 1.73 \mathrm{~m}^{2}$. Time from first-medical record input to randomization was obtained in $210(96.8 \%)$ patients, and it was $2.9 \mathrm{~h}$ in mean, and $2.1 \mathrm{~h}$ in median. Time from patient appearance to randomization and the place they appear was shown in Supplemental Figure 1.

During the first $48 \mathrm{~h}$ from study enrollment, the median administered amount of furosemide-equivalent diuretic dose was $100 \mathrm{mg}$ (IQR, 62.5-160 mg), median total body weight change was $-2.30 \mathrm{~kg}$ (IQR -3.50 to $-1.18 \mathrm{~kg}$ ), and median net fluid loss was $3973.0 \mathrm{~mL}$ (IQR $2566.3-5410.0 \mathrm{~mL}$ ). The median values for the measures of diuretic response were -0.83 (IQR -1.50 to -0.40 ) $\mathrm{kg} /$ $40 \mathrm{mg}$ body weight and 1582.8 (IQR 895-2478.3) mL/ $40 \mathrm{mg}$ net fluid loss. The baseline characteristics of the study population according to diuretic response tertiles are shown in Table 1. Using baseline characteristics, poor diuretic response based on change in body weight, was associated with less edematous status, less history of hypertension, and more hyponatremia. These associations were retained for diuretic response based on net fluid loss. In correlation analysis, change in body weight and net fluid loss showed a statistically significant, but relatively weak correlation (Spearman's rho $=-0.47, P<0.001$ ) (Supplemental Figure 2).
To identify predictors of diuretic response, univariable (Supplemental Table 1) and multivariable linear regression analysis (Table 2) for both parameters were performed. The only independent predictors of a good diuretic response for both criteria were tolvaptan use and a higher diastolic blood pressure. There was no interaction between baseline diuretics and tolvaptan on diuretic response for both BW definition $(P$ value for interaction $=0.816)$ and net fluid loss definition $(P$ value for interaction $=0.642$ ) Likewise, no significant interaction was observed between baseline sodium level, renal function, and impact of tolvaptan treatment on diuretic response (all $P$ value for interaction $>0.20$ ). For both diuretic response definitions, no interaction was found on the effect of tolvaptan on diuretic response between patients who were treated with and without carperitide $(P$ for interaction $=0.137$ with body weight definition and 0.707 with net fluid loss definition).

Patients with a poor diuretic response were less likely to have an improvement in dyspnea relief within $48 \mathrm{~h}$ from randomization, as defined by moderate or marked improvement from baseline according to the seven-point Likert scale (Table 3). A poor diuretic response was also significantly associated with more WRF (Table 3). A worse diuretic response was not associated with an increased risk of pre-specified prognostic endpoints within 90 days.

Figure 1 shows the diuretic response according to randomization group, i.e., with and without tolvaptan treatment. Compared to patients who were not treated with tolvaptan, those who were treated with tolvaptan showed a significantly better diuretic response based on assessment by both body weight change [ -1.16 (IQR -3.00 to -0.57 ) $\mathrm{kg} / 40 \mathrm{mg}$ vs. -0.51 (IQR -1.13 to -0.20 ) $\mathrm{kg} / 40 \mathrm{mg}$; $P<0.001]$ and net fluid loss [2125.0 (IQR 1370.0-3856.3) $\mathrm{mL} / 40 \mathrm{mg}$ vs. 1296.3 (IQR 725.2-1726.5) $\mathrm{mL} / 40 \mathrm{mg}$; $P<0.001]$.

\section{Discussion}

In patients with AHF and renal dysfunction, very early treatment with tolvaptan was independently associated with better diuretic response. AHF patients with poor diuretic response had less dyspnea relief and more frequently experienced worsening renal function.

\section{Diuretic response in AHF}

In spite of the lack of a universal definition, poor response to diuretic therapy has been shown to be one of the most powerful prognostic predictors in patients with heart failure $[4,13,15,16]$. Initial studies used diuretic dose to define 


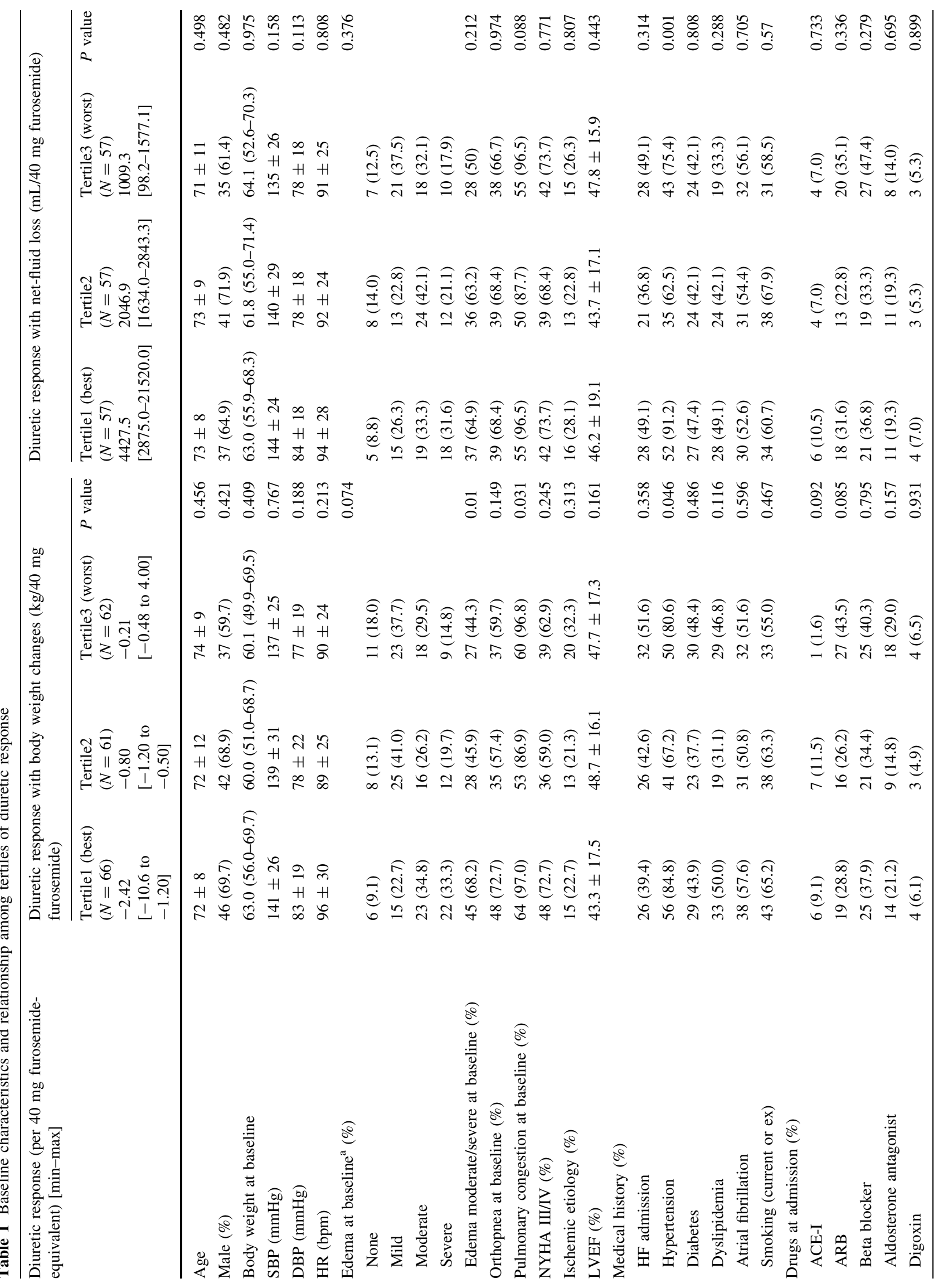




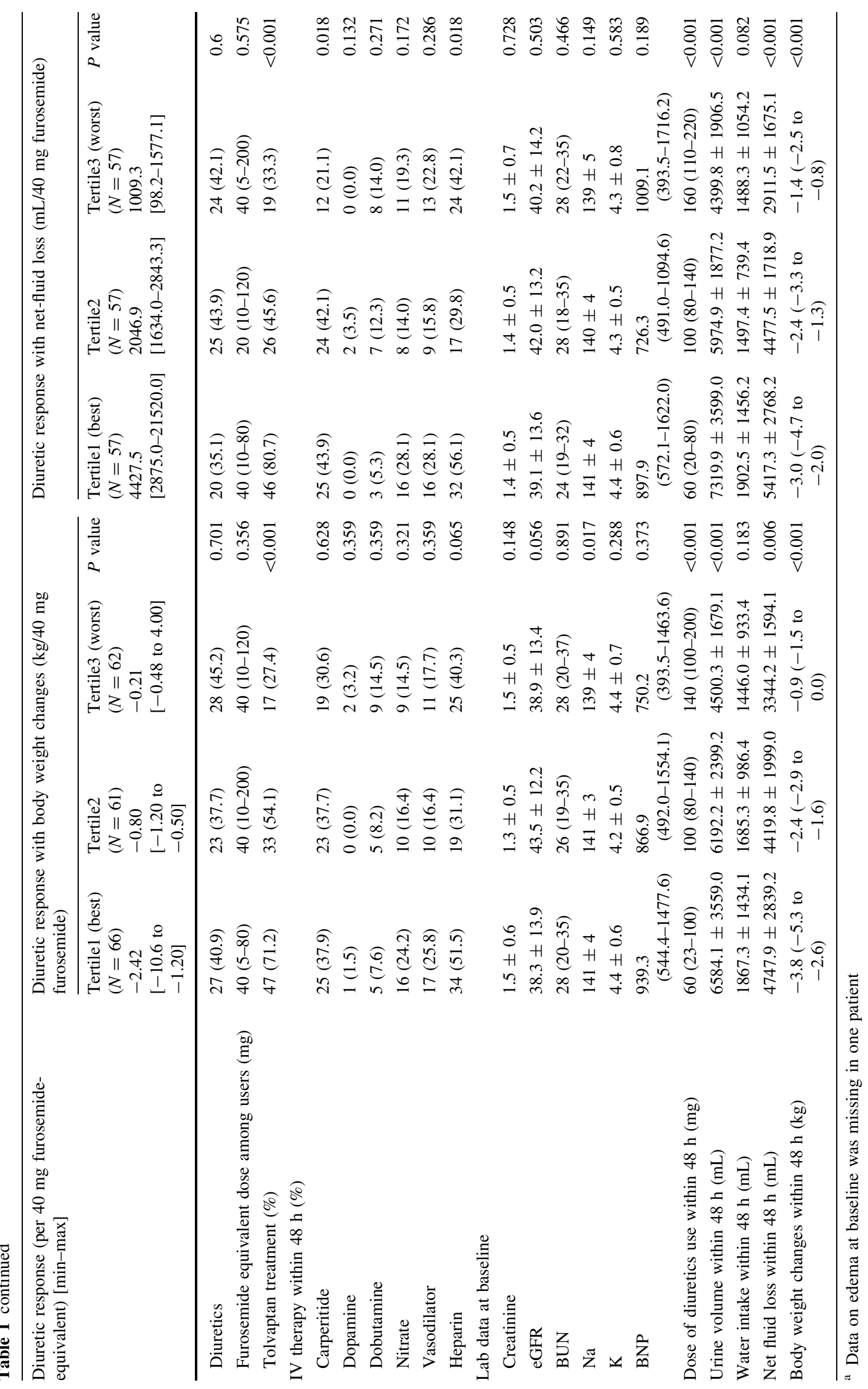


Table 2 Multivariable linear regression analysis of diuretic response

\begin{tabular}{lcrr}
\hline Variable & Standardized beta & $t$ & $P$ value \\
\hline Diuretic response with body & weight changes $(\mathrm{kg} / 40 \mathrm{mg}$ furosemide) \\
Adjusted $R^{2}=0.214$ & & & \\
Tolvaptan treatment & -0.339 & -5.246 & $<0.001$ \\
Heparin IV & -0.241 & -3.707 & $<0.001$ \\
DBP & -0.149 & -2.279 & 0.024 \\
Edema (moderate/severe) & -0.137 & -2.088 & 0.011 \\
Diuretic response with net fluid loss (mL/40 mg furosemide) \\
Adjusted $R^{2}=0.176$ & \multicolumn{3}{c}{} \\
Tolvaptan treatment & 0.387 & 5.495 & $<0.001$ \\
DBP & 0.199 & 2.854 & 0.005 \\
\hline
\end{tabular}

diuretic response, i.e., patients with persistent heart failure despite treatment with a certain dose of diuretics were defined to have a "poor diuretic response" [15, 17]. However, this definition used only amount of diuretics and hereby obviously ignored response to the diuretics and, therefore, assumed equal effectiveness. Recently, a novel definition of diuretic response based on urine/body weight response to a certain amount of diuretics was proposed [6]. In all studies that evaluated its prognostic potential, diuretic response consistently showed significant prognostic ability in patients with AHF when this modified definition was used $[4,5,18,19]$.

There has been no consensus on the parameter used to measure diuretic response to $40 \mathrm{mg}$ furosemide or its equivalent, although recent studies have used either change in body weight, net fluid loss, or total urinary output. In the present study, we showed relatively poor correlation between the two measures of diuretic response. This result was in line with that of the DOSE trial and ASCEND-HF, which demonstrated a poor agreement between net fluid loss and weight loss $[5,20]$. It is clear that we need better measures of diuretic response to encompass natriuretic response, change in volume distribution, and change in hemodynamic status. However, our consistent results on the improvement of diuretic response, by two different parameters, with tolvaptan supported our hypothesis.

According to this novel definition, the median diuretic response was $-0.51 \mathrm{~kg} / 40 \mathrm{mg} / 48 \mathrm{~h}$ furosemide in the conventional group in our study. This was greater than approximately $0.4 \mathrm{~kg} / 40 \mathrm{mg}$ of furosemide-equivalent diuretic response in the patients of the ASCEND-HF (weight change from admission to $48 \mathrm{~h}$ ), RELAX-AHF (weight change from day 1 to 5), and PROTECT (weight change from day 1 to 4$)$ studies $[4,5,18]$. This better diuretic response in this AQUAMARINE cohort did not match our expectations because our study included only AHF patients with renal dysfunction on admission and earlier studies suggest that renal dysfunction predisposes to worse diuretic response $[4,5,18]$. There are several conceivable speculations for this unexpected result. First, lower doses of loop diuretic were given in AQUAMARINE, compared to other studies and the additional effect of a drug usually decreases at higher doses. Second, although baseline creatinine values were higher in the AQUAMARINE cohort than in the ASCEND-HF cohort, levels of baseline blood urea nitrogen were not substantially different between these two studies. Given that blood urea nitrogen, but not creatinine, has been suggested by previous studies as the most powerful determinant of diuretic response $[4,21]$, this may be one of the reasons for discrepancy in our study. Third, median time till randomization from patient arrival was $2.1 \mathrm{~h}$ and $41.4 \%$ of all AQUAMARINE cohort was randomized before admission at the emergency department or clinic. This is surprisingly short given that mean time from admission to randomization was $15.5 \mathrm{~h}$ in ASCEND-HF and $7.9 \mathrm{~h}$ in RELAXAHF [22]. This means AQUAMARINE randomized AHF patients much earlier, and we could, therefore, evaluate diuretic response in the very early phase which was not possible with previous diuretic response studies in AHF cohorts. This difference in the time window might be associated with the unexpected good diuretic response in our study cohort. Finally, our results lead to hypothesis that there may be a racial difference in diuretic response. All of the studies regarding diuretic response so far predominantly enrolled Western AHF patients and little is currently known about diuretic response in Asian AHF patients. This hypothesis is supported by the observation that the amount of intravenous loop diuretics used in the acute phase was very low (around or less than $100 \mathrm{mg} / 48 \mathrm{~h}$ ) in Japanese AHF patients compared to Western patients [12, 23]. Therefore, influence of racial and/or genetic information on diuretic response needs to be elucidated in future studies.

For both diuretic response parameters, high blood pressure was associated with a good diuretic response. These findings were in accordance with the results of previous studies. In the PROTECT, RELAX-AHF, and ASCEND-HF cohorts, low diastolic blood pressure was an independent predictor of poor diuretic response $[4,5,18]$. Interestingly, intravenous unfractionated heparin was associated with good diuretic response measured with body weight. We have no clear explanation for this finding; however, hyperkalemia is known to be a rare but possible complication of heparin therapy [24], and hypokalemia was suggested as an independent predictor of poor diuretic response in PROTECT. Moreover, there is a case report that suggests a direct effect of heparin on diuresis in patients with AHF [25]. The association between intravenous heparin and diuretic response needs to be precisely elucidated in the future studies. 


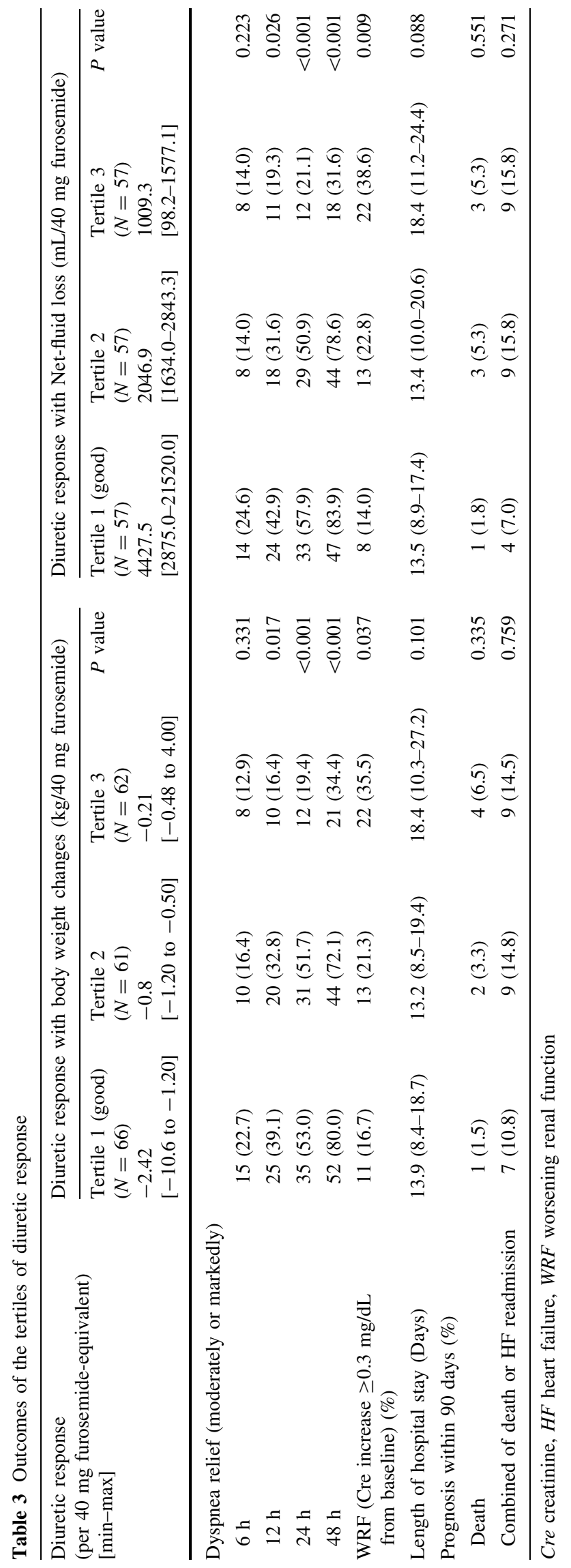


Fig. 1 Diuretic response in patients with acute heart failure according to treatment with tolvaptan. Measurements compared were a change in body weight and $\mathbf{b}$ net fluid loss
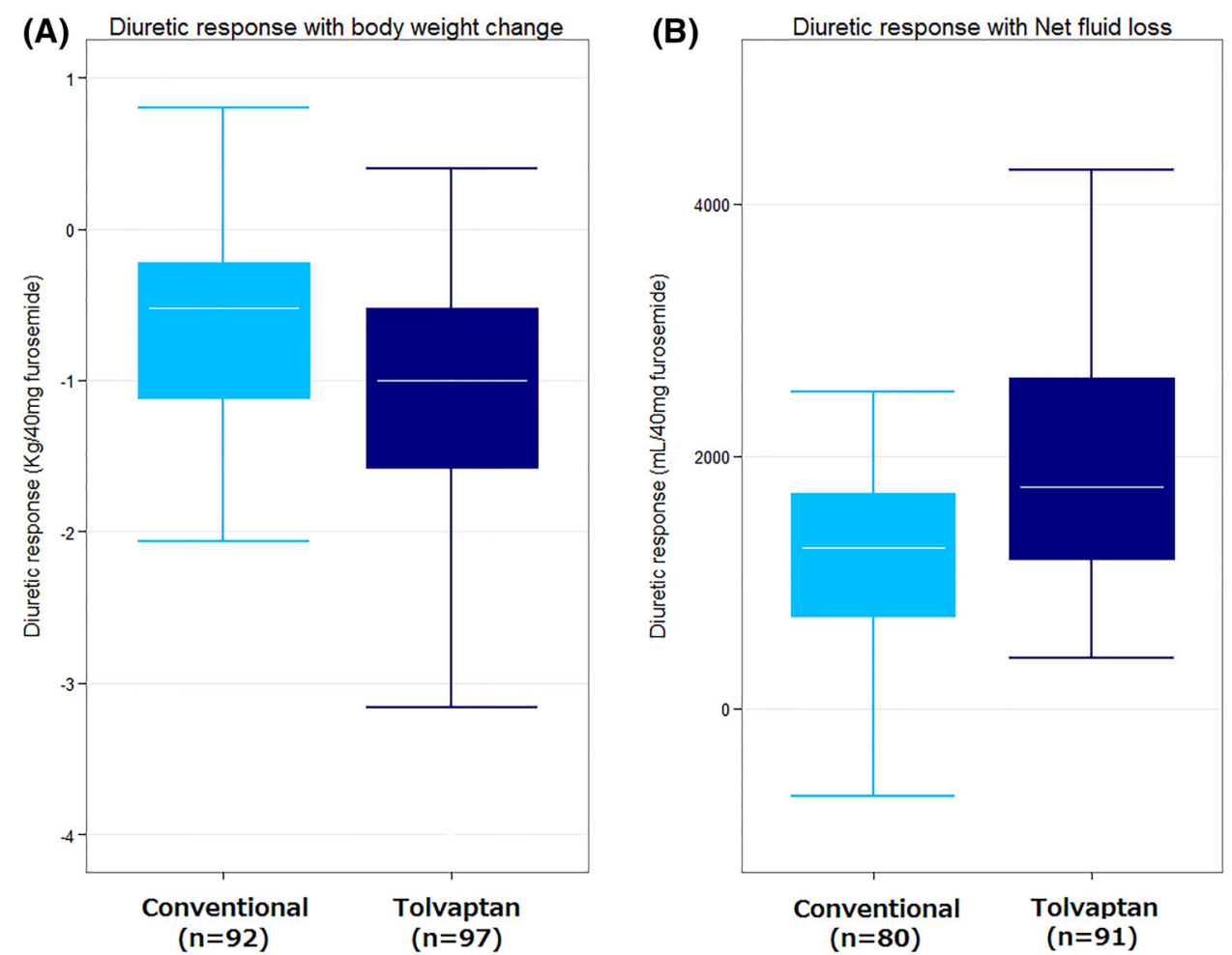

Poor diuretic response was significantly associated with a high incidence of worsening renal function and low rate of improvement in dyspnea at almost all time points. These results are in line with the findings of previous studies [4, 18]; however, it should be acknowledged that the number of events were very small and this study was obviously underpowered to evaluate prognostic significance of diuretic response.

\section{Effect of tolvaptan on diuretic response}

Although some interventions to treat AHF patients with diuretic resistance have been investigated, there has been no proven therapy to improve diuretic resistance in this high risk population. In the ROSE-AHF study, neither lowdose nesiritide nor low-dose dopamine on top of standard of therapy was associated with a greater reduction in body weight within $72 \mathrm{~h}$ [26]. Given that the total amount of furosemide-equivalent diuretic used within $72 \mathrm{~h}$ was not significantly different, neither low-dose dopamine nor lowdose nesiritide was suggested to improve diuretic response. Likewise, in ASCEND-HF, nesiritide did not improve diuretic response [5]. In RELAX-AHF, serelaxin did not show a significant improvement in diuretic response of patients with AHF despite its potentially favorable effects on prognosis $[18,27,28]$. Rolofylline, an adenosine A1receptor antagonist, on the other hand did improve diuretic response [4]. However, its clinical use was hampered by a neutral effect on prognosis and the concern for neurological adverse events. Ultrafiltration might be a promising decongestive strategy [29]; however, it has not been studied specifically in patients with a poor diuretic response.

In the present study, we showed that very early treatment with tolvaptan could improve diuretic response in AHF patients with renal impairment. The pathophysiological background of this favorable effect of tolvaptan on diuretic response remains to be elucidated; however, it may be attributed to certain differences in the mechanisms of action between loop diuretics and tolvaptan. First, timedependent diuretic resistance was observed with loop diuretics. In patients who have been treated with diuretics for a long time, effectiveness is blunted gradually with time [30]. Second, loop diuretics have to be bound to plasma albumin and delivered to the proximal tubules to exert their effects. Therefore, hypoalbuminemia, which is common in patients with AHF, could contribute to poor diuretic response [31, 32]. Third, active secretion of loop diuretics into the lumen via an organic acid transporter is needed for them to act [33]. This transporter could be inhibited by endogenous organic anions [34]. However, compared with furosemide, tolvaptan has a different mechanism of action, i.e., inhibiting the activation of vasopressin- 2 receptor by arginine-vasopressin and subsequent insertion of aquaporin-2 channels in the collecting tubules. This might be one of the reasons for the improvement in diuretic response in renal-impaired patients with AHF after intake of tolvaptan. 
Contrary to our result, recent sub-analysis from EVEREST showed a lack of significant difference in prescription rate of tolvaptan between good/bad diuretic response groups [35]. There are some differences in patient backgrounds between EVEREST and AQUAMARINE that possibly explain this discordance (e.g., racial difference, baseline renal function). However, the most conceivable explanation for this discrepancy is time to treatment. In EVEREST, time from hospitalization to dyspnea assessment (the next calendar day after the first drug administration) was more than $36 \mathrm{~h}$ in $47.7 \%$, and more than $60 \mathrm{~h}$ in $20.2 \%$ [36]. In AQUAMARINE about $40 \%$ of all patients were randomized before admission to the hospital ward and this early capture of AHF patients may lead to short time to randomization and better diuretic response. The association between time to therapy and diuretic response in AHF patient needs to be addressed in future studies.

Tolvaptan is expected to cause aquaresis but not natriuresis. As sodium retention plays a pivotal role in pathophysiology of AHF, aquaresis may have a different impact on prognosis from natriuresis in AHF patients. Although the pathophysiological background of the association between diuretic response and prognosis has yet to be elucidated, early successful decongestion and subsequent symptom relief are plausible mechanisms. Given that several studies, including AQUAMARINE, have consistently showed urine output with tolvaptan (i.e., aquaresis) could also lead to decongestion and subsequent symptom relief, improvement of diuretic response with early treatment with tolvaptan in AHF patients potentially improves outcome. From this perspective, EVEREST might not be suitable to evaluate this hypothesis as tolvaptan was used relatively late and did not improve diuretic response. As we showed improvement in diuretic response with very early treatment with tolvaptan for the first time, future studies on early use of tolvaptan for patients with AHF having poor diuretic response are warranted.

Our study had several limitations; primarily, its openlabel design, which could have influenced some subjective prognostic variables, including relief of dyspnea. This study focused on short-term responses and did not have sufficient power to detect long term differences in WRF. We could not address the association between diuretic response and prognosis because of very little number of events. As we recruited and randomized patients very early in our study, some non-AHF patients might have been included. However, all patients went through careful clinical history taking, physical examination, chest X-ray and analysis of natriuretic. Only after confirmation that patients met the criteria as stated in the protocol, they were randomized and received the study drug. In addition, we performed sensitivity analyses comparing the effects of tolvaptan in patients with a BNP between 100 and $350 \mathrm{pg} / \mathrm{ml}$ and above $350 \mathrm{pg} / \mathrm{mL}$ We found no interaction in the effect of tolvaptan on diuretic response in patients with higher versus lower BNP levels at admission $(P$ value for interaction $=0.183)$. No standardized diuretic regimen was applied and usage of diuretics was at the discretion of the treating physician. Our findings regarding association between diuretic response and dyspnea relief should be interpreted carefully because baseline severity of dyspnea was not evaluated and difference in baseline dyspnea severity between good and poor diuretic response group might affect difference in degree of dyspnea relief.

The most powerful limitation of this study which should be acknowledged is that this is a post hoc and non-prespecified analysis. Moreover, several analyses were performed without adjusting for multiple testing. Given these points, our study result should be interpreted as an exploratory analysis and hypothesis generating.

\section{Conclusions}

Very early treatment with tolvaptan improved diuretic response in patients with a hospital admission for AHF. Future research focusing on the prognostic implication of improving diuretic response with early treatment with tolvaptan in patients with poor diuretic response is warranted.

\section{Compliance with ethical standards}

Funding AQUAMARINE study was funded by Japan Heart Foundation Multicenter Study Grant.

Conflict of interest Dr.Yuya Matsue is supported by JSPS (Japan Society for the Promortion of Science) Overseas Research Fellowship, and received a honorarium from Otsuka Pharmaceutical Co. Dr. Makoto Suzuki received lectures honoraria from Bayer, Otsuka Pharmaceutical Co., Biotronik Japan Co., Daiichi-Snakyo, Medtronic Japan Co., Ltd., St. Jude Medical Japan, and Fukuda Denshi. Dr. Yuichi ono received lectures honoraria from Medtronic Japan Co., Ltd. Dr. Kazuki Yoshida receives tuition support jointly from the Japan Student Services Organization and Harvard T. H. Chan School of Public Health (partially supported by training Grants from Pfizer, Takeda, Bayer, and PhRMA). Dr. Kaoru Sugi received scholarship fund from Daiichi-Sankyo Pharmaceutical and lectures honoraria from Bayer. Dr. Steven R. Goldsmith received consulting fees, speaking fees, and research support from Otsuka USA and OtsukaJapan. The other authors have nothing to disclose related to this paper.

Open Access This article is distributed under the terms of the Creative Commons Attribution 4.0 International License (http://crea tivecommons.org/licenses/by/4.0/), which permits unrestricted use, distribution, and reproduction in any medium, provided you give appropriate credit to the original author(s) and the source, provide a link to the Creative Commons license, and indicate if changes were made. 


\section{References}

1. Adams KF Jr, Fonarow GC, Emerman CL, LeJemtel TH, Costanzo MR, Abraham WT, Berkowitz RL, Galvao M, Horton DP, ASA Committee Investigators (2005) Characteristics and outcomes of patients hospitalized for heart failure in the United States: rationale, design, and preliminary observations from the first 100,000 cases in the acute decompensated heart failure national registry (ADHERE). Am Heart J 149:209-216

2. Mentz RJ, Kjeldsen K, Rossi GP, Voors AA, Cleland JG, Anker SD, Gheorghiade M, Fiuzat M, Rossignol P, Zannad F, Pitt B, O'Connor C, Felker GM (2014) Decongestion in acute heart failure. Eur J Heart Fail 16:471-482

3. Ambrosy AP, Fonarow GC, Butler J, Chioncel O, Greene SJ, Vaduganathan M, Nodari S, Lam CS, Sato N, Shah AN, Gheorghiade M (2014) The global health and economic burden of hospitalizations for heart failure: lessons learned from hospitalized heart failure registries. J Am Coll Cardiol 63:1123-1133

4. Valente MA, Voors AA, Damman K, Van Veldhuisen DJ, Massie BM, O'Connor CM, Metra M, Ponikowski P, Teerlink JR, Cotter G, Davison B, Cleland JG, Givertz MM, Bloomfield DM, Fiuzat M, Dittrich HC, Hillege HL (2014) Diuretic response in acute heart failure: clinical characteristics and prognostic significance. Eur Heart J 35:1284-1293

5. ter Maaten JM, Dunning AM, Valente MA, Damman K, Ezekowitz JA, Califf RM, Starling RC, van der Meer P, O'Connor CM, Schulte PJ, Testani JM, Hernandez AF, Tang WH, Voors AA (2015) Diuretic response in acute heart failure-an analysis from ASCEND-HF. Am Heart J 170:313-321

6. ter Maaten JM, Valente MA, Damman K, Hillege HL, Navis G, Voors AA (2015) Diuretic response in acute heart failurepathophysiology, evaluation, and therapy. Nat Rev Cardiol 12:184-192

7. Gheorghiade M, Konstam MA, Burnett JC Jr, Grinfeld L, Maggioni AP, Swedberg K, Udelson JE, Zannad F, Cook T, Ouyang J, Zimmer C, Orlandi C, Efficacy of Vasopressin Antagonism in Heart Failure Outcome Study With Tolvaptan I (2007) Short-term clinical effects of tolvaptan, an oral vasopressin antagonist, in patients hospitalized for heart failure: the EVEREST clinical status trials. JAMA 297:1332-1343

8. Peacock WF, Costanzo MR, De Marco T, Lopatin M, Wynne J, Mills RM, Emerman CL, ASA Committee Investigators (2009) Impact of intravenous loop diuretics on outcomes of patients hospitalized with acute decompensated heart failure: insights from the ADHERE registry. Cardiology 113:12-19

9. Wong YW, Mentz RJ, Felker GM, Ezekowitz J, Pieper K, Heizer G, Hasselblad V, Metra M, O'Connor CM, Armstrong PW, Starling RC, Hernandez AF (2016) Nesiritide in patients hospitalized for acute heart failure: does timing matter? Implication for future acute heart failure trials. Eur J Heart Fail 18:684-692

10. Ponikowski P, Voors AA, Anker SD, Bueno H, Cleland JG, Coats AJ, Falk V, Gonzalez-Juanatey JR, Harjola VP, Jankowska EA, Jessup M, Linde C, Nihoyannopoulos P, Parissis JT, Pieske B, Riley JP, Rosano GM, Ruilope LM, Ruschitzka F, Rutten FH, van der Meer P, Authors/Task Force M, Document R (2016) 2016 ESC Guidelines for the diagnosis and treatment of acute and chronic heart failure: The Task Force for the diagnosis and treatment of acute and chronic heart failure of the European Society of Cardiology (ESC). Developed with the special contribution of the Heart Failure Association (HFA) of the ESC. Eur J Heart Fail 18:891-975

11. Matsue Y, Suzuki M, Nagahori W, Yoshida K, Onishi Y, Satoh Y, Ono Y, Nishioka T, Noda M, Sugi K, Torii S, Tejima T, Sakurada H, Yamaguchi S, Okishige K, Fujii H, Takahashi A (2014) Clinical effectiveness of tolvaptan in patients with acute decompensated heart failure and renal failure: design and rationale of the AQUAMARINE study. Cardiovasc Drugs Ther 28:73-77

12. Matsue Y, Suzuki M, Torii S, Yamaguchi S, Fukamizu S, Ono Y, Fujii H, Kitai T, Nishioka T, Sugi K, Onishi Y, Noda M, Kagiyama N, Satoh Y, Yoshida K, Goldsmith SR (2016) Clinical effectiveness of tolvaptan in patients with acute heart failure and renal dysfunction. J Card Fail 22:423-432

13. Testani JM, Brisco MA, Turner JM, Spatz ES, Bellumkonda L, Parikh CR, Tang WH (2014) Loop diuretic efficiency: a metric of diuretic responsiveness with prognostic importance in acute decompensated heart failure. Circ Heart Fail 7:261-270

14. Scheen AJ, Vancrombreucq JC, Delarge J, Luyckx AS (1986) Diuretic activity of torasemide and furosemide in chronic heart failure: a comparative double blind cross-over study. Eur J Clin Pharmacol 31(Suppl):35-42

15. Neuberg GW, Miller AB, O'Connor CM, Belkin RN, Carson PE, Cropp AB, Frid DJ, Nye RG, Pressler ML, Wertheimer JH, Packer M, Evaluation PIPRAS (2002) Diuretic resistance predicts mortality in patients with advanced heart failure. Am Heart J 144:31-38

16. Ferreira JP, Girerd N, Medeiros PB, Santos M, Carvalho HC, Bettencourt P, Kenizou D, Butler J, Zannad F, Rossignol P (2016) Spot urine sodium excretion as prognostic marker in acutely decompensated heart failure: the spironolactone effect. Clin Res Cardiol 105:489-507

17. Hasselblad V, Gattis Stough W, Shah MR, Lokhnygina Y, O'Connor CM, Califf RM, Adams KF Jr (2007) Relation between dose of loop diuretics and outcomes in a heart failure population: results of the ESCAPE trial. Eur J Heart Fail 9:1064-1069

18. Voors AA, Davison BA, Teerlink JR, Felker GM, Cotter G, Filippatos G, Greenberg BH, Pang PS, Levin B, Hua TA, Severin T, Ponikowski P, Metra M, Investigators R-A (2014) Diuretic response in patients with acute decompensated heart failure: characteristics and clinical outcome-an analysis from RELAXAHF. Eur J Heart Fail 16:1230-1240

19. Aronson D, Burger AJ (2016) Diuretic response: clinical and hemodynamic predictors and relation to clinical outcome. J Card Fail 22:193-200

20. Testani JM, Brisco MA, Kociol RD, Jacoby D, Bellumkonda L, Parikh CR, Coca SG, Tang WH (2015) Substantial discrepancy between fluid and weight loss during acute decompensated heart failure treatment. Am J Med 128(776-783):e774

21. ter Maaten JM, Valente MA, Metra M, Bruno N, O'Connor CM, Ponikowski P, Teerlink JR, Cotter G, Davison B, Cleland JG, Givertz MM, Bloomfield DM, Dittrich HC, van Veldhuisen DJ, Hillege HL, Damman K, Voors AA (2016) A combined clinical and biomarker approach to predict diuretic response in acute heart failure. Clin Res Cardiol 105:145-153

22. Cannon JA, McKean AR, Jhund PS, McMurray JJ (2015) What can we learn from RELAX-AHF compared to previous AHF trials and what does the future hold? Open Heart 2:e000283

23. Matsue Y, Kagiyama N, Yoshida K, Kume T, Okura H, Suzuki M, Matsumura A, Yoshida K, Hashimoto Y (2015) Carperitide is associated with increased in-hospital mortality in acute heart failure: a propensity score-matched analysis. J Card Fail 21:859-864

24. Bengalorkar GM, Sarala N, Venkatrathnamma PN, Kumar TN (2011) Effect of heparin and low-molecular weight heparin on serum potassium and sodium levels. J Pharmacol Pharmacother 2:266-269

25. Targonski R, Sadowski J, Cyganski PA (2014) Impact of anticoagulation on the effectiveness of loop diuretics in heart failure with cardiorenal syndrome and venous thromboembolism. Blood Coagul Fibrinolysis 25:180-182

26. Chen HH, Anstrom KJ, Givertz MM, Stevenson LW, Semigran MJ, Goldsmith SR, Bart BA, Bull DA, Stehlik J, LeWinter MM, 
Konstam MA, Huggins GS, Rouleau JL, O’Meara E, Tang WH, Starling RC, Butler J, Deswal A, Felker GM, O'Connor CM, Bonita RE, Margulies KB, Cappola TP, Ofili EO, Mann DL, Davila-Roman VG, McNulty SE, Borlaug BA, Velazquez EJ, Lee KL, Shah MR, Hernandez AF, Braunwald E, Redfield MM, Network NHFCR (2013) Low-dose dopamine or low-dose nesiritide in acute heart failure with renal dysfunction: the ROSE acute heart failure randomized trial. JAMA 310:2533-2543

27. Filippatos G, Farmakis D, Metra M, Cotter G, Davison BA, Felker GM, Greenberg BH, Hua TA, Pang PS, Ponikowski P, Qian M, Severin TA, Voors AA, Teerlink JR (2017) Serelaxin in acute heart failure patients with and without atrial fibrillation: a secondary analysis of the RELAX-AHF trial. Clin Res Cardiol. doi:10.1007/s00392-016-1074-X

28. Liu LC, Voors AA, Teerlink JR, Cotter G, Davison BA, Felker GM, Filippatos G, Chen Y, Greenberg BH, Ponikowski P, Pang PS, Prescott MF, Hua TA, Severin TM, Metra M (2016) Effects of serelaxin in acute heart failure patients with renal impairment: results from RELAX-AHF. Clin Res Cardiol 105:727-737

29. Costanzo MR, Saltzberg MT, Jessup M, Teerlink JR, Sobotka PA (2010) Ultrafiltration Versus Intravenous Diuretics for Patients Hospitalized for Acute Decompensated Heart Failure I. Ultrafiltration is associated with fewer rehospitalizations than continuous diuretic infusion in patients with decompensated heart failure: results from UNLOAD. J Card Fail 16:277-284
30. Ellison DH (2001) Diuretic therapy and resistance in congestive heart failure. Cardiology 96:132-143

31. Brater DC (1998) Diuretic therapy. N Engl J Med 339:387-395

32. Pichette V, Geadah D, du Souich P (1996) The influence of moderate hypoalbuminaemia on the renal metabolism and dynamics of furosemide in the rabbit. $\mathrm{Br} \mathrm{J}$ Pharmacol 119:885-890

33. Wilcox CS (2002) New insights into diuretic use in patients with chronic renal disease. J Am Soc Nephrol 13:798-805

34. Sweet DH, Bush KT, Nigam SK (2001) The organic anion transporter family: from physiology to ontogeny and the clinic. Am J Physiol Renal Physiol 281:F197-F205

35. Ter Maaten JM, Valente MA, Damman K, Cleland JG, Givertz MM, Metra M, O'Connor CM, Teerlink JR, Ponikowski P, Bloomfield DM, Cotter G, Davison B, Subacius H, van Veldhuisen DJ, van der Meer P, Hillege HL, Gheorghiade M, Voors AA (2016) Combining diuretic response and hemoconcentration to predict rehospitalization after admission for acute heart failure. Circ Heart Fail. doi:10.1161/CIRCHEARTFAILURE.115.002845

36. Pang PS, Konstam MA, Krasa HB, Swedberg K, Zannad F, Blair JE, Zimmer C, Teerlink JR, Maggioni AP, Burnett JC Jr, Grinfeld L, Ouyang J, Udelson JE, Gheorghiade M, Efficacy of Vasopressin Antagonism in Heart Failure Outcome Study with Tolvaptan I (2009) Effects of tolvaptan on dyspnoea relief from the EVEREST trials. Eur Heart J 30:2233-2240 